\title{
IMPROVEMENT OF HIGHWAY WORK ZONE PERFORMANCE BY TRAFFIC MANAGEMENT
}

\author{
Ghassan. Suleiman* \\ Department of Civil Engineering, Aqaba University of Technology, \\ P.O.Box 11947, Aqaba, Jordan \\ Ahmad M. Dahamsheh \\ Department of Civil Engineering, Aqaba University of Technology, \\ P.O.Box 11947, Aqaba, Jordan \\ Department of Civil Engineering, Alhussein Bin Talal University, \\ P.O.Box 71111, Maan, Jordan \\ Murat Ergun \\ Department of Civil Engineering, Technical University of Istanbul, \\ P.O.Box 34469, Istanbul, Turkey \\ *Corresponding Author
}

\begin{abstract}
This study investigates the effects of traffic management strategies on performance of a work zone along arterial roads. The strategies included Temporary Access Control (TAC), Limitation of Heavy Vehicles (LHV) and Lanes Management (LM). Study area was conducted on Queen Rania Al-Abdullah Arterial Street (QRAA) in Amman, the Capital of Jordan. Traffic volume was collected through field observation during morning rush hours. Then, a micro simulation model was developed based on empirical traffic data using VISSIM software. The simulation model has been validated using different parameters. The analysis showed that the average delay was highly affected by a lot of factors like percent of heavy vehicles, flow from access roads, parking, driver behavior and lanes monitoring. Moreover, the average delay was 113.5 second/vehicle and average speed was $17 \mathrm{~km} / \mathrm{hr}$. furthermore, speed has decreased from $22 \mathrm{~km} / \mathrm{hour}$ before work zone to $10.1 \mathrm{~km} / \mathrm{hour}$ at work zone (-54 \%) . On the other hand, by applying the traffic management strategies, both of delay and speed were improved. For instance, average delay was decreased from 113.5 to 89 second/vehicle (-22\%) and average speed showed improvement by $30 \%$ (from 22 to 29) $\mathrm{km} / \mathrm{hr}$.
\end{abstract}

Keywords: Delay, Traffic, Simulation, Speed, VISSIM, Work Zone 
Cite this Article: Ghassan. Suleiman, Ahmad M. Dahamsheh and Murat Ergun, Improvement of Highway Work Zone Performance by Traffic Management, International Journal of Civil Engineering and Technology, 11(10), 2020, pp. 22-30. https://iaeme.com/Home/issue/IJCIET?Volume $=11 \&$ Issue $=10$

\section{INTRODUCTION AND LITERATURES REVIEWS}

The last decade has seen a rapid growth in urban areas in both developed and developing countries. The growth in urban size increases the demand for travel and requires an expansion or improvement of the existing transport networks [1]. However, several obstacles such as insufficient resources, waves of forced migration and current urban forms may prevent the expansion or improvement of the existing networks. However, construction of such facilities usually is accompanied by sudden congestion and traffic jam in the work zones. Highway Capacity Manual (HCM) [2] defined the work zone as "an area of highway in which maintenance and construction operations are taking place that impinge on the number of lanes available to moving traffic or affect the operational characteristics of traffic flowing through the area.".

Several studies have been developed models to evaluate recurrent delay or queue rather than the delay caused by work zone [3]. For instance, rainfall, heavy vehicles and police presence were found to reduce capacity of work zones [4]. Also, the capacity was influenced by the lane closures and by the work zone activities (trucks, presence of workers) [5]. Furthermore, the effect of heavy truck was analyzed by [6]. His work showed that increasing the heavy truck percentage will increase the headway which reduces the road capacity. One of the most approaches to decrease delays and improve traffic flow is the access or ramp metering. Ramp metering is an efficient strategy for improving traffic flow along the mainline by controlling vehicles entering from access roads into the mainline traffic [7]. Also, monitoring of vehicles entering to mainline by access metering strategies realized balance demand and capacity, as well as improving traffic mobility and delay level [8]. However, operating strategies such as using the shoulder area and temporarily reducing the width of the existing lanes to form additional lanes can be used to alleviate infrequent traffic congestion at work zone [9]. All negative impacts of lane-changing maneuvers due to blocked lanes on traffic condition like congestion level, flow density and existing flow rate is tested by macroscopic traffic simulation method [10]. Information about driver compliance, merging behavior, speed differentials, lane changing, and braking maneuvers are extracted to be used in the simulation calibration for temporary ramp meters at seven work zones [11].

\section{STUDY AREA}

Amman, the capital of Jordan has a population of about 4.5 million [12]. Rapid growth of Amman population may be justified as a result of the concentration of most business, malls, universities and sudden immigration as a result of crisis in the Middle East. These sudden growths push the decision makers to develop alternative solutions to absorb its impacts in terms of traffic jams. Consequently, one of these solutions was constructing of High Speed Bus Line (HSBL) along Queen Rania Al-Abdullah Arterial (QRAA) Street. The QRAA is extended along of $7.2 \mathrm{~km}$ approximately. The construction operations of HSBL resulted in regeometric design of QRAA. In addition, a lot of bridges have been constructed to avoid the comprehensive separation for HSBL of normal traffic. Based on the above, a lot of work zones were occured during construction of HSBL. This study focused on analysis of a one work zone in Amman that is starting from Sweileh to the Dawreiat intersection with distance of $2.5 \mathrm{~km}$. 
The work zone area is located on QRAA Street, entering side to the city. The arterial consists of 4-Lane, parking is temporary permitted along the right lane. In addition, one part of the right lane on QRAA is occupied by the minibuses as a waiting area of the public ring transportation buses. Moreover, in the middle work zone, a new bridge between Dawreiat and Sweileh intersections is under constructing. The construction operations resulted in decreasing number of lanes from four to three lanes. Finally, three access local two-direction roads are found along the study area as shown in figure 1.

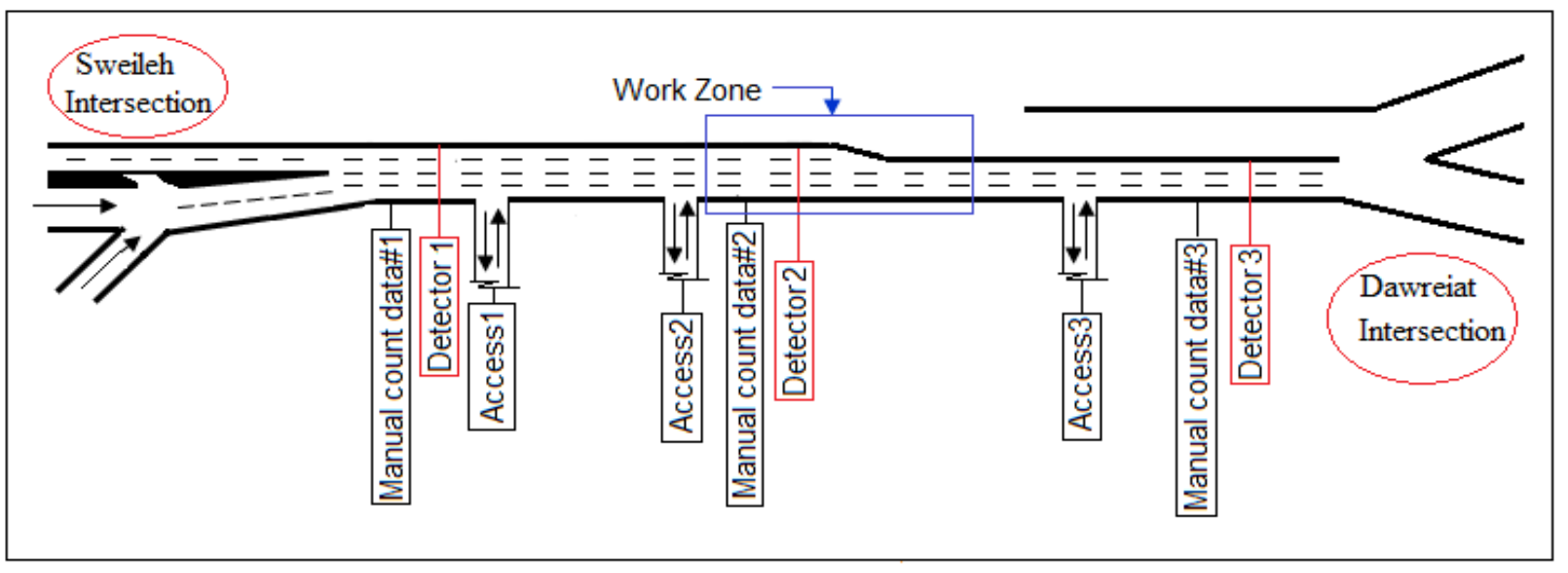

Figure 1 Schematic view of the study area.

\section{METHODOLOGY}

\subsection{Data Collection}

Data of traffic volume was recorded through field observation. Three recording points (\#1, 2, 3 ) were used to collect access volumes that are entering to the QRAA at morning rush hours between 7:00-9:00 AM. The morning peak of 7:00-9:00 AM was selected to cover the business time in Jordan which starts at 8:00 to 8:30 AM (according to work sector). Moreover, volumes before, at and after work zone were measured to be used in model calibration. All volumes were collected manually using manual hand counter. Then, the collected volumes are divided into three groups as passenger car, minibuses and heavy vehicles. Collection points are shown in figure1. Finally, all volumes are measured at interval of 15-minut period.

\subsection{Simulation Model (Calibration and Validity)}

First step is to build model using VISSIM software and setting the calibration. The model calibration process, model parameters are altered until a qualitative and a quantitative balance between the simulation and the observation is reached. Traditionally, calibration requires several runs based on engineering judgment and experience [13]. Vehicle inputs like vehicle type, acceleration and deceleration rate, reduced speed limits area and priorities for traffic in conflicting areas all these parameters are taken into consideration due to their effects the simulation model. In this study, calibration of (Origin-Destination) OD estimation was applied. Furthermore, the collected data were verified, employing the GEH method, which is widely adopted for a variety of analytical purposes in traffic engineering, traffic forecasting, and traffic modeling [14]. The formula for the GEH statistics is expressed below: 


$$
\mathrm{GEH}=\sqrt[2]{\frac{\left(V O L_{o b s}-V O L_{s i m}\right)^{2}}{\left(V o l_{o b s}-V O L_{\text {sim }}\right) / 2}}
$$

$\mathrm{VOL}_{\mathrm{obs}}$ and $\mathrm{VOL}_{\text {sim }}$ are traffic volume from the observation and the simulation respectively. For traffic modeling work in the "baseline" scenario, a GEH of less than 5.0 is considered a good match between the modeled and observed volumes, and $85 \%$ of the volumes in a traffic model should have a GEH less than 5.0 [20]. In our study, The GEH value is below the limit values (value is 3.1) thus the simulation model developed is considered as representative. Traffic flow data from simulated model are collected from three detectors $(1,2$ and 3$)$ as shown in figure 1 . The comparison between the real and simulated case for detectors ( 1 and 2 ) is presented below in figures 2 and 3 respectively.

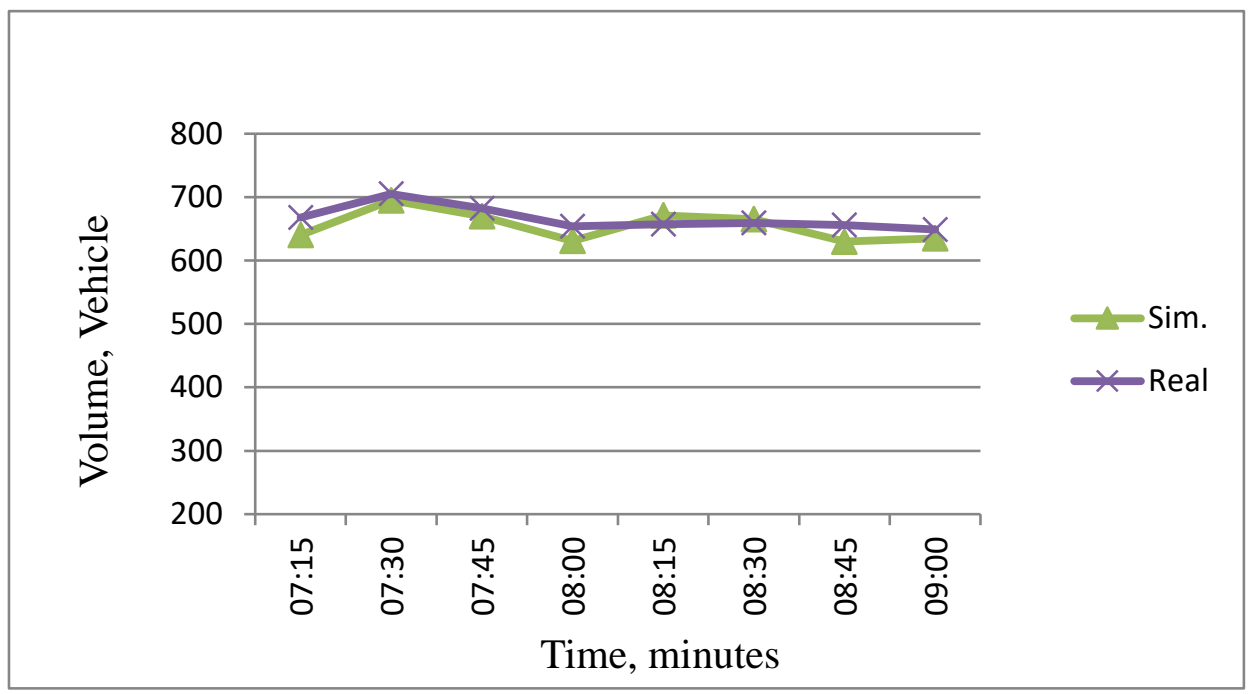

Figure 2 Comparison between volume of real and simulation case from detector \#2

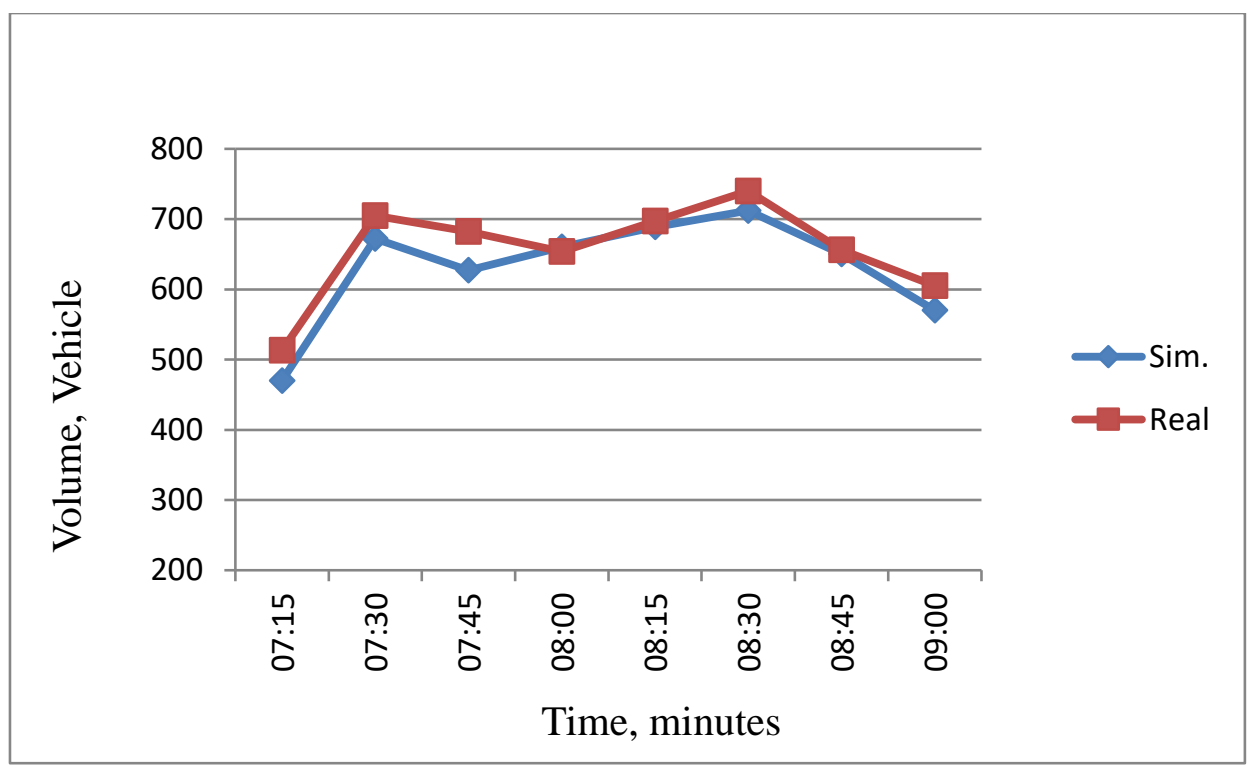

Figure 3 Comparison between volume of real and simulation case from detector \#3 


\section{RESULTS AND DISCUSSION}

\subsection{Evaluation of Real Case}

The analysis of real case shows that the average speed at network is $17 \mathrm{~km} / \mathrm{h}$ and the average delay is equal to 113.5 seconds/vehicle. Also, the average speed has decreased to from 22 $\mathrm{km} / \mathrm{hr}$ before work zone (at collection point \#1) to $10.1 \mathrm{~km} / \mathrm{hr}$ at work zone $(-54 \%)$. The speed variations between three detectors $\left(\mathrm{D}_{1}, \mathrm{D}_{2}\right.$ and $\left.\mathrm{D}_{3}\right)$ are presented in figure4. The reduction in speed after detector 1 caused by traffic maneuvering on the right lane from (in/out) flow (from / to) the access roads. Unfortunately, existing of parking even for limited time resulted in occupying the right lane for several minutes. Consequently, the capacity of the right lane on arterial is decreased and finally resulted in speed reduction. On the other hand, the permission of heavy vehicles to use arterials during rush hour contributed to reducing both of traffic flow and speed as well as increasing travel time when proportion of heavy vehicles rises in each lane [14]. Accordingly, it was necessary to implementing several traffic management strategies to improve the performance of work zone area.

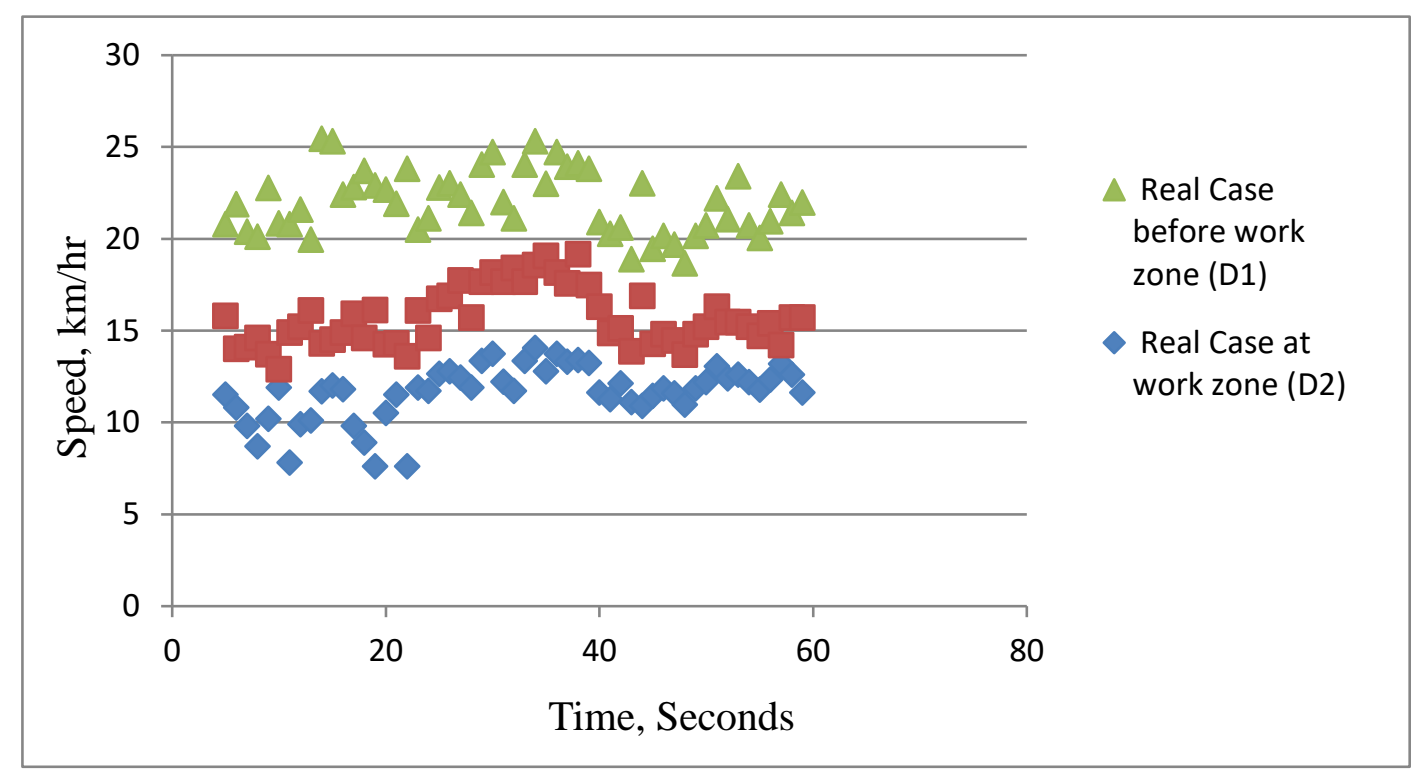

Figure 4 Speed analysis for real case at detectors (before, at and after work zone)

\subsection{Impact of Temporary Access Control (TAC)}

The applied traffic management is summarized by three strategies. These strategies included Temporary Access Control (TAC), Limitation of Heavy Vehicle (LHV) and Lanes Management (LM). In the fact, the delays of vehicle on arterials increases as the volume from I to access roads are increased due to increasing of merging, diverging and maneuvering operations. Consequently, increasing of space headway then decreasing of capacity and rising in traffic delay. The (AC) strategy aims to avoiding or reducing congestion on QRAA by converting access roads directions from two to one direction. On the next step, using temporary access metering which may motivate drivers to use adjacent or parallel road network instead of an arterial [15]. This technique resulted in reduction of congestion and delays from 113.5 to 102.1 second/vehicle $(-10 \%)$. On the other hand, average speed has increased from 22 to $26 \mathrm{~km} / \mathrm{hr}(+18.1 \%)$. The effect of Access Control (AC) on network speed is shown in figure 5 . 


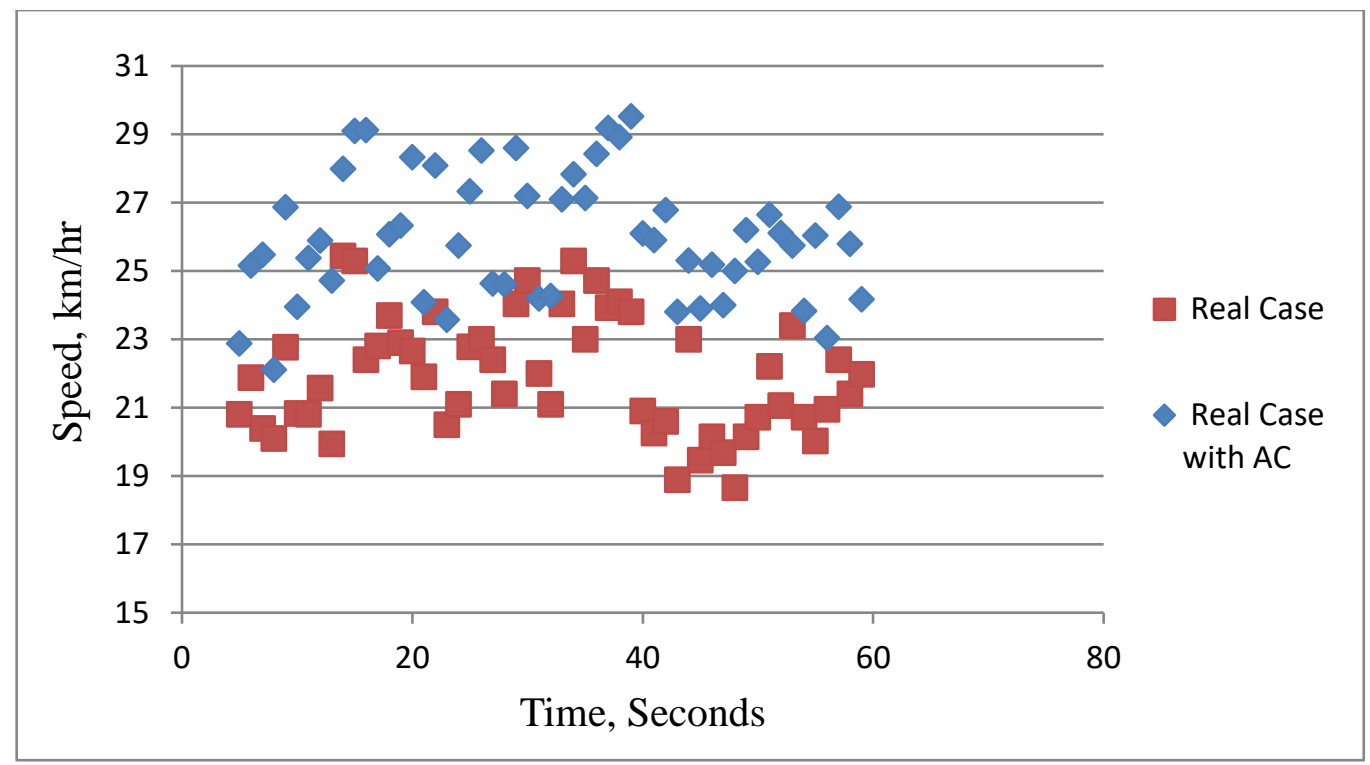

Figure 5 Effect of (AC) strategy on average speed.

\subsection{Impact of (LHV) and (LM) Strategies}

Although heavy vehicles make up a small proportion of vehicle traffic, they are known to have a significant impact on traffic flow, especially on upgraded road sections and work zone. The traffic impacts of heavy vehicles can be more serious on arterial roads because of traffic interruption caused by intersections [16] [17]. In this study, percent of heavy vehicles represents one-seventh of the fleet. The (LHV) strategy included transferring heavy vehicles to the city ring road and completely preventing using the arterial along morning peak hours. While, the (LM) included forcing minibuses group to use the right lane only and forbidding them to use the middle and left lanes during morning peak hours. This technique led to an increase of speed by about $11 \%$. Furthermore, the average delay has decreased from 113.5 to 97.5 seconds/vehicles $(-14 \%)$. The reason of this reduction related to the fact that the heavy vehicles have low deceleration and acceleration rate with low brake response and slow maneuverability. Also, heavy vehicles have highly physically and psychologically negative impacts on drivers in adjacent lanes [18] [19]. Moreover, lanes changing become impossible, and inclusion of new heavy vehicles forces the existing traffic to slow down to provide the required gaps. As mentioned earlier, the traffic delay will decrease accompanied by enhancement both of speed and traffic flow. The effect of Limitation of Heavy Vehicle (LHV) is presented in figure 6 . 


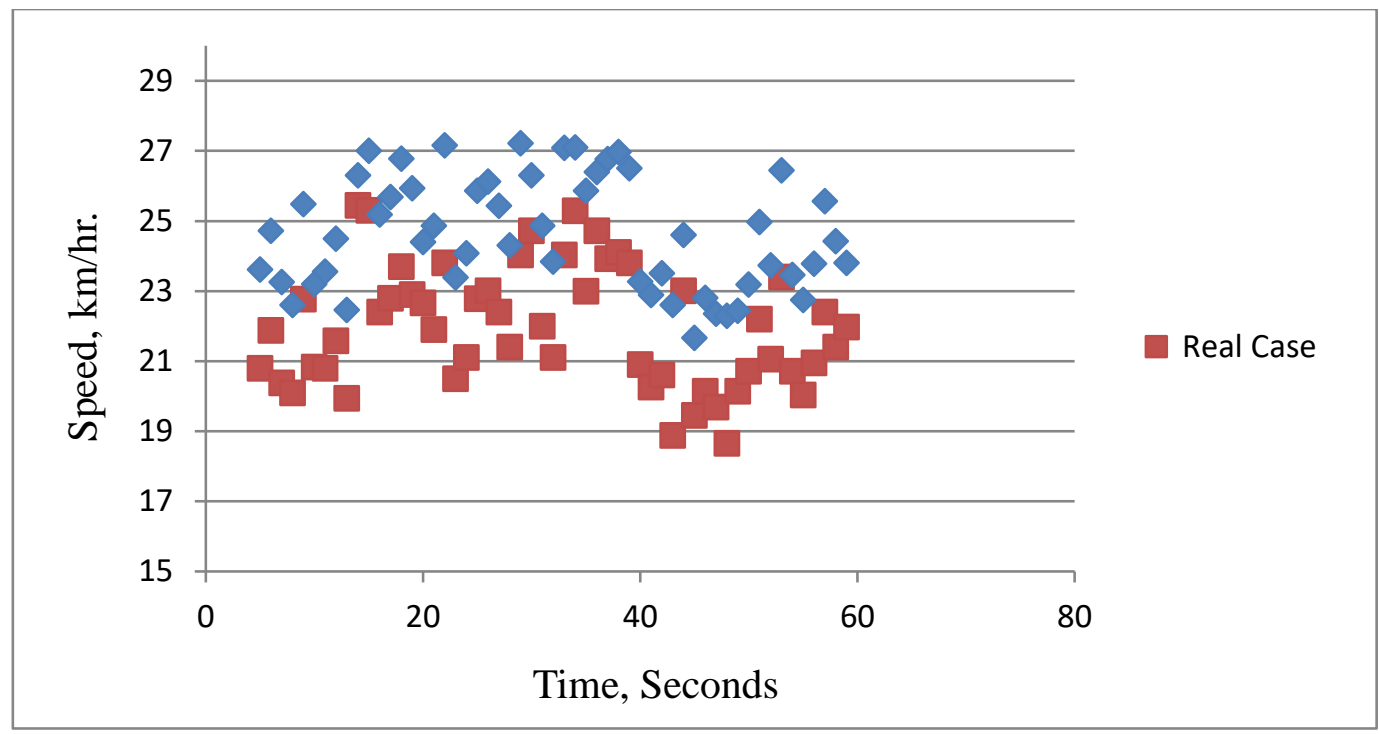

Figure 6 Effect of (LHV) and (LM) strategies on average speed.

In simulation model, several scenarios with different heavy vehicle percent were tested to check the impacts of heavy vehicles on throughput average. The result is presented in figure 7.

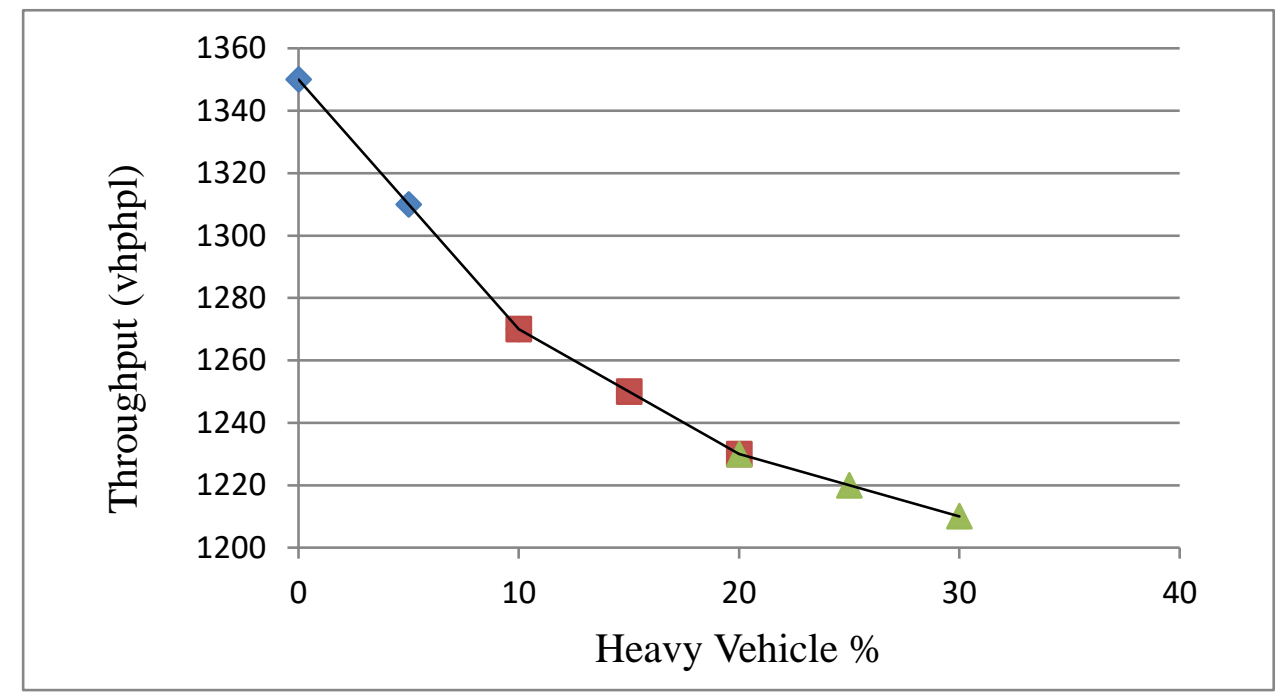

Figure 7 Throughput vs. heavy vehicle percent.

\subsection{Impact of all Management Strategies}

The impact of all strategies is presented in figure 8. According to the figure, a clear improvement was observed in speed where average speed has increased from 22 to 28.6 $\mathrm{km} / \mathrm{hr}$ (30 \%). On the other hand, average delay is decreased from 113.5 to 89 seconds/vehicles $(-22 \%)$. 


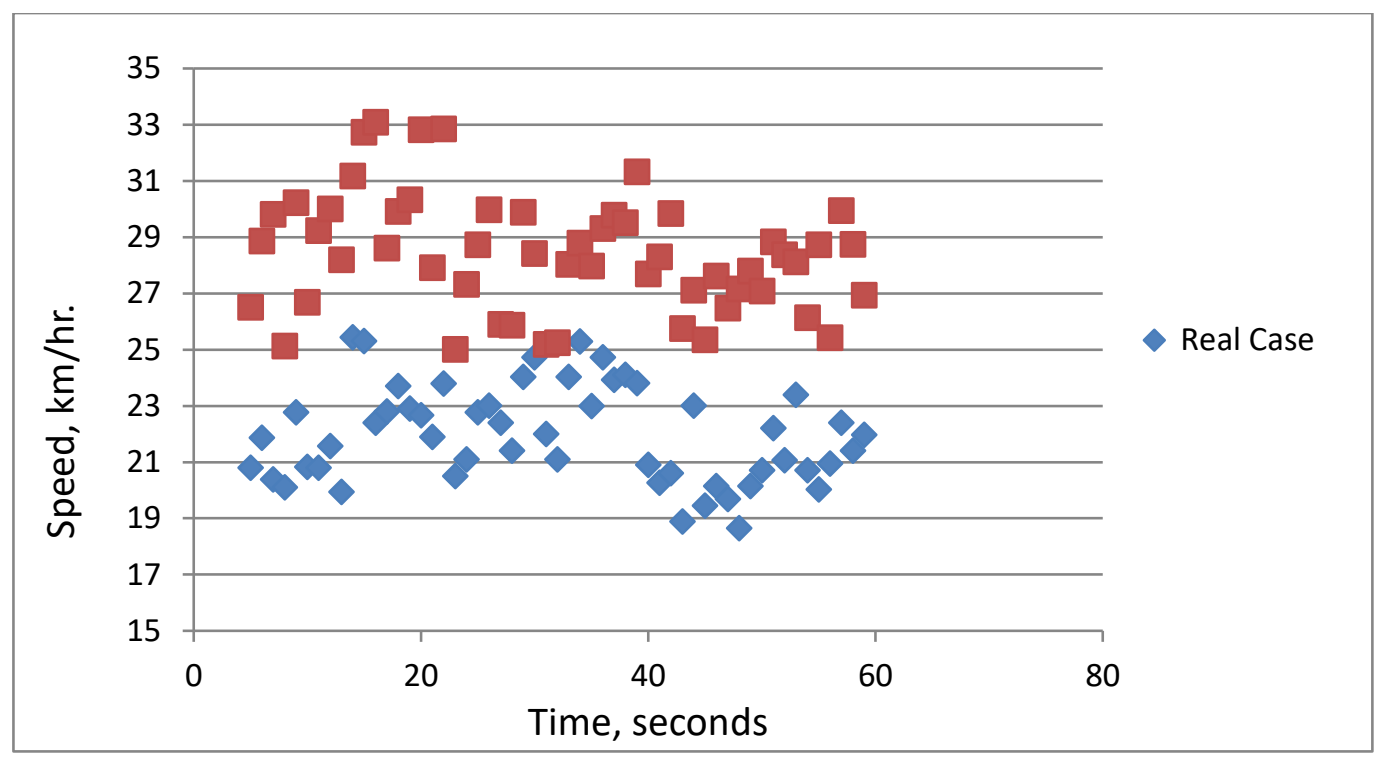

Figure 8 Effect of (AC) and (LHV) strategies on average speed.

\section{CONCLUSION}

This study foxed on analysis of performance of work zone along arterial roads. Furthermore, enhancement of this performance by applying different traffic management strategies. The following points were concluded that might have wider application:

- Work zone is highly affected by traffic flow from block access along the arterial ecpecially when these accesss road are two directional.

- The average delay for real condition at whole network was 113.6 seconds/vehicle and average speed $22 \mathrm{~km} / \mathrm{hr}$.

- The average speed has decreased from $22 \mathrm{~km} / \mathrm{hr}$ before work zone to $10.6 \mathrm{~km} / \mathrm{hr}$ at work zone.

- After applying of (AC), (LHV) and (LM) traffic mangement stratigies, average delay is decreased from 113.5 to 89 seconds/vehicle $(-22 \%)$.

- Average speed showed improvement by $30 \%$ (from 22 to 28.6 ) $\mathrm{km} / \mathrm{hr}$.

\section{REFERENCES}

[1] Al-Masaeid, Hashem R., and Ghassan Suleiman. "Relationships between urban planning variables and traffic crashes in Damascus." Road \& Transport Research 13.4 (2004): 63.

[2] Manual, Highway Capacity. "TRB special report 209." National Research Council, Washington, DC (1994).

[3] Cottrell, Wayne D. "Empirical freeway queuing duration model." Journal of transportation engineering 127.1 (2001): 13-20.

[4] Venugopal, Shyam, and Andrzej Tarko. "Investigation of factors affecting capacity at rural freeway work zones." 80th Annual Meeting of the Transportation Research Board, Washington, DC. 2001.

[5] Richards, Stephen H., and Conrad L. Dudek. "Field evaluation of traffic management strategies for maintenance operations in freeway middle lanes." Transportation research record 703 (1979): 31-36.

[6] Cunagin, Wiley D., and Edmund Chin-Ping Chang. Effects of trucks on freeway vehicle headways under off-peak flow conditions. No. 869. 1982. 
[7] Hardy, Matthew, and Karl Wunderlich. Traffic Analysis Toolbox Volume VIII, Work Zone Modeling and Simulation: A Guide for Decision-Makers. No. FHWA-HOP-08-029. United States. Federal Highway Administration. Office of Operations, 2008.

[8] Sankar, Param, et al. Work Zone Impacts Assessment-An Approach to Assess and Manage Work Zone Safety and Mobility Impacts of Road Projects. No. FHWA-HOP-05-068. United States. Federal Highway Administration. Office of Operations, 2006.

[9] Lee, Chanyoung, David A. Noyce, and Xiao Qin. "Development of traffic delay assessment tool for short-term closures on urban freeways." Transportation Research Record 2055.1 (2008): 39-48.

[10] Chang, Gang-len, and Zuojin Zhu. "A macroscopic traffic model for highway work zones: formulations and numerical results." Journal of advanced transportation 40.3 (2006): 265-287.

[11] Oner, E. (2009). An Evaluation of Entrance Ramp Metering for Freeway Work Zones using Digital Simulation (Doctoral dissertation, Ohio University).

[12] http://dosweb.dos.gov.jo/population/population-2.

[13] Suleiman, Ghassan M., et al. "Effects of speed management and roadway parameters on traffic flow along arterials." Proceedings of the Institution of Civil Engineers-Transport. Vol. 170. No. 6. Thomas Telford Ltd, 2017.

[14] Moridpour, Sara, Ehsan Mazloumi, and Mahmoud Mesbah. "Impact of heavy vehicles on surrounding traffic characteristics." Journal of advanced transportation 49.4 (2015): 535-552.

[15] Haj-Salem, Habib, and Marcos Papageorgiou. "Ramp metering impact on urban corridor traffic: Field results." Transportation Research Part A: Policy and Practice 29.4 (1995): 303319.

[16] Al-Kaisy, Ahmed, Younghan Jung, and Hesham Rakha. "Developing passenger car equivalency factors for heavy vehicles during congestion." Journal of transportation engineering 131.7 (2005): 514-523.

[17] Aghabayk, Kayvan, et al. "Comparing heavy vehicle and passenger car lane-changing maneuvers on arterial roads and freeways." Transportation research record 2260.1 (2011): 94101.

[18] Gates, Timothy J., and David A. Noyce. "Dilemma zone driver behavior as a function of vehicle type, time of day, and platooning." Transportation Research Record 2149.1 (2010): 8493.

[19] Chu, Kang-Ching, et al. "Validation of stochastic traffic flow model with microscopic traffic simulation." 2011 IEEE International Conference on Automation Science and Engineering. IEEE, 2011.

[20] Younes, Mohammad K., Ghassan Sulaiman, and Ali Al-Mashni. "Integration of Traffic Management and an Artificial Intelligence to Evaluate Urban Air Quality." Asian Journal of Atmospheric Environment (AJAE) 14.3 (2020). 